\title{
A decadência do patriarcado em crônica da casa assassinada (1959), de Lúcio Cardoso
}

The decay of patriarchy in crônica da casa assassinada (1959), by Lúcio Cardoso

\author{
Kariny Ranelli Tavares Dutra \\ Joelma Siqueira Santana ${ }^{2}$
}

Resumo: O presente ensaio analisa a obra Crônica da Casa Assassinada (1959), de Lúcio Cardoso, à luz dos estudos de Gilberto Freyre sobre a família patriarcal no Brasil, propondo que o tema da decadência do patriarcado tem efeito sobre a economia interna da obra, que dialoga com ideias de Freyre e de outros estudiosos da sociologia, sem que esta possa ser vista como espelho ou representação da sociedade.

Palavras-chave: Lúcio Cardoso; Crônica da casa Assassinada; Família patriarcal; Literatura e sociedade.

\section{Introdução}

O patriarcado exprime sua ordem em todas as esferas sociais: família, religião, política, educação, artes, etc. e está na base social e, portanto, cultural, da maioria das sociedades ocidentais. Como parte da cultura, nós o encontramos em muitos bens simbólicos, seja de forma refletida ou responsiva. Com Raymond Williams, podemos entender a cultura não mais como reflexo imediato da base capitalista, cuja estrutura baseia-se no patriarcado, mas, como resposta a ela. A cultura pode responder de maneira positiva, reproduzindo e reforçando os padrões basilares da sociedade, ou negativa, produzindo artigos e formas que confrontem o sistema estabelecido. Dessa forma, é possível a produção de uma arte revolucionária, no sentido restrito da palavra, aquela em que percebemos a consciência, não só de classe, mas também das relações de gênero.

1 Graduada em Letras pela Universidade Federal de Viçosa. Mestranda em Estudos Literários pela Universidade Federal de Juiz de Fora; dutrakariny@gmail.com.

2 Doutora em Literatura Brasileira (USP); Professora associada da Universidade Federal de Viçosa; jandrausufv@gmail.com. 
A obra Crônica da casa assassinada (1959), de Lúcio Cardoso, pode ser lida como um desmascaramento da ordem patriarcal da família mineira. O romance aborda a decadência econômica e social de uma antiga e prestigiada família, nomeada Meneses. A narrativa se constitui de relatos diversos, produzidos por diferentes personagens em primeira pessoa, possibilitando-nos observar como se percebem e como percebem o outro dentro de uma estrutura social na qual a família exerce papel delimitador de identidades: o patriarca, a esposa, o filho, o agregado, etc. Afirmar que Cardoso compreendia a arte nesse sentido revolucionário proposto por Williams ou pela crítica feminista atual seria, no mínimo, discutível. No entanto, o escritor revelou um objetivo político com a publicação de sua obra durante entrevista concedida a Fausto Cunha para o Jornal do Brasil em 25 de novembro de 1960:

\footnotetext{
Meu movimento de luta, aquilo que busco destruir e incendiar pela visão de uma paisagem apocalíptica e sem remissão, é Minas Gerais. Meu inimigo é Minas Gerais. O punhal que levanto, com a aprovação ou não de quem quer que seja, é contra Minas Gerais. Que me entendam bem: contra a família mineira. Contra a literatura mineira. Contra a concepção de vida mineira. Contra a fábula mineira. Contra o espírito bancário que assola Minas Gerais. Enfim, contra Minas, na sua carne e no seu espírito (CARDOSO, 1960).
}

O escritor é enfático ao evidenciar certo interesse político com o projeto de "destruir" Minas Gerais. Sua afirmação certamente denota um sentido metafórico, um ataque simbólico no âmbito da cultura: "literatura", "família", "fábula", "concepção de vida" e "espírito" mineiros, permitindo-nos analisar, hoje, a Crônica a partir dos Estudos Culturais e feministas, especificamente suas contribuições sobre os temas família, gênero e patriarcado. Esses conceitos foram melhor delineados posteriormente com a ascensão dos estudos feministas e o advento da New Left a partir dos anos 60; porém, eles já tinham sido discutidos por importantes estudiosos brasileiros quando da publicação da obra de Lúcio Cardoso. Lembremo-nos das publicações de Casa grande e senzala (1933) e Sobrados e Mucambos (1936), de Gilberto Freyre, que tratam sobre essas questões no período colonial e início da República, respectivamente. Falaremos mais adiante sobre a tese de Freyre e sua relação com o romance.

A publicação de Crônica e sua declarada pretensão, ao expô-la a público, retoma a crítica em torno do autor: Lúcio Cardoso deixa de ser um romancista social a partir de A luz no subsolo (1936) e torna-se romancista intimista? Seu último romance revê tal classificação como veremos ao longo deste artigo. Ler sua obra sem considerar os elementos sociais ali presentes é um erro que talvez tenha contribuído para situá-lo como escritor periférico na historiografia literária de seu tempo, época em que o romance social era o modelo ideal do 
gênero. A problemática da decadência do patriarcado não está presente somente como tema na obra, mas, também, como parte fundamental de sua estrutura narrativa.

Em Crônica da casa assassinada o emprego da primeira pessoa do discurso, o aprofundamento psicológico das personagens e polifonia devem ser avaliados como elementos fundamentais à medida que servem de base para a criação de um todo simbólico: a família patriarcal mineira em ruína, ficcionalmente, os Meneses. Reputar o escritor dentro de uma literatura intimista ou de uma literatura social tem sido um erro recorrente em leituras superficiais que pecam por não avaliarem forma e conteúdo como partes de um mesmo signo, indivisíveis. Assim, procuramos com o presente trabalho entender a decadência do patriarcado mineiro expresso na família Meneses atento à forma e ao conteúdo da narrativa na medida em que se inter-relacionem. Olhamos para a Crônica como um importante romance social construído a partir das subjetividades das personagens.

\section{A história da família patriarcal brasileira: o caso Meneses}

Com frequência, os estudos sobre a família brasileira, tanto nas ciências sociais quanto na história, recuperam os trabalhos de Gilberto Freyre (1933; 1936), seja para questioná-los, seja para expandi-los. O que torna sua leitura imprescindível. Em Casa grande e senzala (1933) - obra considerada primordial para a sociologia brasileira, Freyre examina diversos aspectos tidos por ele como formadores da sociedade e da identidade brasileiras. Em um primeiro momento, ele faz referência às diferenças nos modelos coloniais ingleses e espanhóis com relação ao modelo português, o autor também aborda questões de miscigenação, assim como a questão da promiscuidade e da relação (de posse) de homens e mulheres no contexto colonial. Enfim, o autor traça um retrato bem detalhado dos costumes, hábitos e papéis desempenhados pelos diferentes atores sociais durante o período colonial no Brasil. Ainda nesse texto, Freyre elabora a tese sobre a formação do Brasil cuja base estaria na consolidação e expansão do modelo familiar patriarcal durante a Colônia. Com isso, ele cristaliza o conceito de "família patriarcal brasileira", entendido como um grupo extenso de pessoas ligadas consanguineamente e liderado por um patriarca detentor do poder, da propriedade e dos escravos.

A segunda parte da história progressiva da família é contada por Freyre na publicação de Sobrados e mucambos (1936). O segundo livro é uma análise sociológica do momento 
posterior à sociedade colonial das famílias patriarcais. O subtítulo do volume anuncia o fim desse modelo familiar: "Decadência do patriarcado rural e desenvolvimento do urbano".

Seguindo sua lógica, a família patriarcal esteve no cerne da formação do Brasil, num contexto rural e colonial, e teve seu fim com o início da urbanização e industrialização. A família patriarcal daria lugar então ao modelo urbano de família: o nuclear ${ }^{3}$. Essa nova configuração tornaria as relações de poder mais horizontais, o patriarca perde parte de seu poder, além de alterar significativamente a condição da mulher, que agora passa a ter maior autonomia inserindo-se no mercado de trabalho e tendo conquistado o direito ao voto a partir de 1932.

As pesquisas mais recentes sobre família têm criticado a característica idealista do texto de Freyre. Um ensaio importante a esse respeito intitula-se Repensando a família patriarcal brasileira (1981) que foi publicado por Mariza Corrêa. A estudiosa argumenta que o paradigma patriarcal não era o único e nem predominante em números. Ela não nega a existência do modelo patriarcal, mas defende que ele foi escolhido pelo autor de Casa grande como fundante da nação por ser um modelo idealizado encontrado no pensamento das classes dominantes. Assim, detendo-se também no ensaio "The Brazilian Family" (1972), de Antonio Candido, destaca que,

Ao modelar a história da sociedade brasileira sobre a forma familiar vigente nas camadas 'senhoriais', recuperando teoricamente as práticas sociais que analisam (a dominação masculina e a subordinação da mulher, o casamento entre parentes, etc.), utilizam essa análise para demonstrar a importância daquela família, seu suposto, na sociedade assim constituída à sua imagem. Em ambos os casos, seu tempo concedido à sua dominação é por demais amplo, o espaço social onde se inscrevem essas unidades familiares é demasiado estreito (CORRÊA, 1981, p. 7).

A historiografia da família tem se baseado nos pressupostos teóricos freyreanos, fator que, para a autora, evidencia a história dos dominantes e fixa um padrão de família. Repousa sobre Freyre a crítica de sua abordagem potencialmente ideal sobre o tema do patriarcado, posicionamento que pode ser também encontrado ao tratar da miscigenação e identidade nacional. Portanto, ao enaltecer uma conjuntura histórica, Freyre diminui outras potencialidades conjecturais do tempo em que está analisando. Logo, ao abordar o patriarcado, o autor se esquece de outras variações ocorridas nos diferentes grupos sociais no que diz respeito à instituição da família.

3 Gilberto Freyre, ao traçar a história de formação e queda da família patriarcal, converge com as teorias da Escola de Chicago. A escola estudou a passagem da sociedade rural para a urbana na virada do século XIX para o XX e as consequências da urbanização e desenvolvimento do capitalismo na estrutura familiar predominante até o século XIX, ou seja, a família patriarcal. É difícil estabelecer tal relação de influência, porém, é dado que Robert Park, eminente sociólogo da Escola, aparece em três referências bibliográficas de Freyre (1936).

Gláuks: Revista de Letras e Artes - jul./ dez. 2019 - Vol 19, No 2, ISSN 2318-7131 
O mesmo tratamento é dado ao caráter relacional entre as estruturas locais e regionais dentro do contexto geral brasileiro. As famílias do Nordeste condizem em estrutura, formação e características com os modelos da mesma época em outros estados ou regiões? Freyre não sugere esse movimento em nenhum sentido. Dessa forma, o que temos é um padrão ideal estagnado na figura do patriarcado - e na sua decadência - sertanejo e nordestino, ignorando outros modelos nos quais poderiam ser transpostos não apenas questões raciais, mas também de gênero e de poder. Em suma, novas pesquisas sobre a(s) família(s) brasileira(s) pretendem romper com a generalização do modelo familiar e evidenciar a pluralidade dessas estratificações (SOUZA; BOTELHO, 2001).

A ruptura com a generalidade freyreana nos possibilita compreender a decadência do patriarcado a partir de sua gênese teórica, os próprios textos de Freyre. Contudo, ao mesmo tempo permite-nos saltar em direção a um posicionamento mais acentuado de suas especificidades com relação ao contexto regional e local. No nosso caso, estamos falando do contexto mineiro do início do século XX. Sendo assim, é impossível transferir todas as nuances elaboradas por Freyre sem que haja um filtro, coisa que a obra de Lúcio Cardoso faz ao empregar a forma narrativa polifônica e fragmentada para afirmar características locais. $\mathrm{O}$ que proporciona a quebra de uma visão genérica da família brasileira.

Ao afirmar uma decadência da família patriarcal, em Sobrados e mucambos, há a presunção de que houve um momento em que sua estrutura esteve intacta. O que pode ser confirmado na leitura da obra anterior, Casa grande e senzala. É nesse ponto que delimitamos as aproximações e distanciamentos entre Crônica da casa assassinada, os estudos de Freyre (1933; 1936) e Corrêa (1981). Cardoso elabora um romance que evidencia a ruína do patriarcado em Minas a partir de uma representação verossímil com a sociedade narrada por Freyre. Vários elementos da família patriarcal aparecem na narrativa através de aspectos relacionados ao espaço e tempo, mas, de maneira mais relevante, por meio da construção das personagens. Um estudo minucioso poderia ser feito a fim de estabelecer as ligações entre os textos sociológicos de Gilberto e o ficcional, a lista de semelhanças seria enorme. Ao ler Crônica após uma leitura atenta de Freyre $(1933 ; 1936)$ é possível criar a hipótese de que Lúcio Cardoso se baseou nas teses freyreanas. Entretanto, a narrativa revela uma novidade epistemológica, periférica na obra do sociólogo.

Quando conseguimos traçar linearmente a história da família Meneses, vemos que as fissuras em sua estrutura patriarcal são antigas. A fim de averiguar tal elaboração, é indispensável que tracemos o perfil dos membros dessa família. O enredo nos traz 
informações fragmentadas de quatro gerações de Meneses: (1) Maria Sinhá, tia-avó; (2) Dona Malvina, mãe; (3) Demétrio, Valdo e Timóteo - filhos; e (4) André, neto.

As duas primeiras gerações aparecem de maneira tangencial na narrativa. As personagens femininas são evocadas como assunto em alguns diálogos no texto. A ascendência mais antiga é também a mais emblemática. Maria Sinhá é comparada a Anita Garibaldi: "Maria Sinhá vestia-se de homem, fazia longos estirões a cavalo, ia de Fundão a Queimados em menos tempo do que o melhor dos cavaleiros da fazenda" (CARDOSO, 2012, p. 46-47). Crônica aborda questões, hoje discutidas como identidade de gênero, por meio da construção das personagens Maria Sinhá e de Timóteo. Entretanto, ao evocar tais sujeitos para dentro do seio familiar patriarcal, Lúcio Cardoso divulga uma face escondida do patriarcado. Os padrões que envolvem as identidades de gênero e estabelecem os papéis do homem e da mulher são desejáveis na sociedade patriarcal; porém, convivem com "desvios".

Dona Malvina aparece em várias menções ao passado (ao todo, vinte e uma vezes) em falas por vezes nostálgicas. Através desses trechos conhecemos um pouco sobre a função que ocupava na família e a rotina da chácara naqueles tempos. Algumas citações relacionam sua figura à prática religiosa, às festividades dos feriados, ao relacionamento com os vizinhos e ao cuidado do imóvel. Porém, a referência que mais nos interessa é a seguinte:

Sem dar grande atenção a minha resposta, ele [Demétrio] continuou: - Considere que depois da morte de nossa mãe, nada fizemos para aumentar o dinheiro que nos deixou - ou melhor, só fizemos negócios errados. E temos vivido unicamente de rendas que já se acham praticamente esgotadas (CARDOSO, 1979, p. 425).

A partir do trecho acima, supomos que Malvina era responsável pela administração das finanças da família, sendo ela a provedora dos filhos já que vivem da herança deixada por ela. Em nenhum momento seu marido é nomeado nesta posição, pelo contrário, ele é apagado da história dos Meneses. O apagamento do patriarca é um dos pontos principais da obra cardosiana.

A terceira geração que conhecemos compõe o núcleo principal dos Meneses: os três irmãos Demétrio, Valdo e Timóteo. O irmão mais velho, Demétrio, reivindica a autoridade de patriarca para si depois da morte dos pais. Após a morte de Dona Malvina, ele tenta administrar as finanças e a moral da casa, interferindo em todo assunto que circunda a parentela. Mesmo assim, ele é o único que não assume o papel de narrador do romance, ou seja, ele não tem voz na narrativa. O que sabemos dele é contado pelas outras personagens, principalmente nas confissões de sua esposa, Ana. O silenciamento do patriarca, ou aspirante a, é repetido nas figuras do pai e do primogênito. Valdo, assim como Demétrio, defende a

Gláuks: Revista de Letras e Artes - jul./ dez. 2019 - Vol 19, $N^{o} 2$, ISSN 2318-7131 
honra e tradição da família, dentro de concepções conservadoras. Ele é influenciado pelo irmão em diversas situações, levando-nos a crer que seja ele o único a levar a cabo as orientações e mandos do primogênito. De certa forma, ele se torna um porta-voz do irmão e do conservadorismo.

O outro irmão, Timóteo, é antagônico aos demais. O personagem ganhou público ao ser interpretado por Carlos Kroeber na adaptação do romance para o cinema, $A$ casa assassinada (1971) - direção de Paulo Cesar Saraceni. As cenas dos Meneses é uma das mais aclamadas no cinema brasileiro pela atuação de Kroeber, que venceu vários prêmios de melhor ator. Timóteo é identificado afim ao que hoje reconheceríamos pelo nome de “travesti”. Com a morte de Malvina herdou roupas, joias e maquiagem da mãe. Assim, pôde assumir sua identidade de gênero e, por isso, é intimado pelos irmãos a se isolar a fím de não ser visto por ninguém, nem mesmo pelos empregados e familiares. O desprezível e o que está fora da norma são claramente ignorados e escondidos pelos Meneses.

Por fim, a última geração de Meneses existe somente no plano discursivo, sustentado por informações adulteradas. O herdeiro, André, é apresentado como filho de Valdo e Nina, sua esposa. Contudo, ele é filho de Ana e Alberto, jardineiro da chácara. A mãe biológica esconde de todos a real filiação do filho, fazendo com que a esperança de renovação familiar seja uma ilusão. O sucessor da família é um bastardo, um Meneses ilegítimo.

Dito isso, Cardoso se aproxima do olhar teórico que Corrêa imprime sobre o assunto. Ainda que crie uma família aos moldes da caracterização freyreana, o romancista mineiro evidencia que sua "decadência" era inevitável, uma vez que seus alicerces nunca foram estáveis. Assim, retomemos às palavras do escritor proferidas na entrevista publicada no Jornal do Brasil: "Ah, mas eu a terei [Minas Gerais] escrava do que surpreendi na sua imensa miséria, no seu imenso orgulho, na sua imensa hipocrisia" (CARDOSO, 1960). O estado de Minas Gerais é a representação do patriarcado na ficção, logo, a miséria, o orgulho e a hipocrisia são qualificações que se atribuem também à família patriarcal. Ao qualificar Minas desta maneira, o escritor converge para o que defende a socióloga: o modelo patriarcal de família é mais ideal do que real na sociedade brasileira.

O paradigma familiar dos Meneses revela a hipocrisia denunciada por seu autor na entrevista. Desde a primeira geração é possível perceber uma alteração na estrutura central do patriarcado, a inversão (ou subversão?) dos papéis e funções preestabelecidos por este modelo. Dona Malvina aparece como provedora e figura central da casa. Além disso, a tentativa de Demétrio assumir o papel de patriarca é frustrada. Ele não consegue controlar as

Gláuks: Revista de Letras e Artes - jul./ dez. 2019 - Vol 19, $N^{o}$ 2, ISSN 2318-7131 
finanças nem a imoralidade (segundo sua própria concepção de vida) fecunda na rotina de seus "subordinados". Seu fracasso é expressado formalmente na Crônica pela ausência de sua voz na narrativa. Por fim, o último Meneses é um filho bastardo. A "família patriarcal brasileira" é um modelo idealizado a ser alcançado.

\section{O protagonismo feminino em Crônica}

As personagens femininas exercem papéis fundamentais na narrativa, como vimos brevemente, tanto do ponto de vista formal quanto na criação simbólica. Ao entendermos a Crônica como parte de um projeto de desconstrução das estruturas patriarcais que sustentam a sociedade mineira, não consideramos apenas a temática apresentada. Tampouco pretendemos transpor a sociologia para o texto literário. Nesta seção analisaremos os aspectos formais da narrativa que sustentam a leitura proposta no presente trabalho.

A principal característica do romance é a polifonia. Ele é composto por cinquenta e seis capítulos divididos irregularmente entre nove narradores-personagens e escritos em diferentes gêneros textuais (cartas, diários, memórias, confissões, depoimentos). As várias vozes da narrativa são responsáveis por narrar o mistério que circuncida a família, ou seja, como revela o título, o assassinato da casa. As falas determinantes são das personagens femininas do tempo presente da narrativa: Ana e Nina. São através das cartas de Nina e das confissões de Ana que descobrimos o mistério em torno da ruína dos Meneses. A valorização das vozes femininas e o apagamento das vozes masculinas dos "patriarcas" (Demétrio e o pai) invertem a ordem patriarcal. Diferente do que acontece com Dom Casmurro (1899), de Machado de Assis, são as próprias mulheres que contam sua versão da história. Na Crônica não há dúvida sobre o adultério, ele é confessado pelas personagens femininas. A relevância da comparação não está no fato da traição ou da confissão, mas na mudança de paradigma entre os dois autores. O que torna Lúcio Cardoso nosso contemporâneo em sentido restrito.

A característica polifônica da obra cria uma subjetivação dos dados factuais. Evandro Nascimento (2002) elege o conceito de polifonia de Mikhail Bakhtin para afirmar que "no romance de Lúcio não é a realidade (ficcional) que 'enquadra' os personagens, mas são eles que aparecem como 'consciências autônomas' (dando um sentido bastante especial a essa expressão), através dos quais a factualidade é filtrada" (p. 165). Os fatos passam pelo filtro da memória e da consciência dos narradores-personagens, nenhum narrador tem ciência de todos

Gláuks: Revista de Letras e Artes - jul./ dez. 2019 - Vol 19, $N^{o}$ 2, ISSN 2318-7131 
os acontecimentos e noção da totalidade dos fatos. A realidade ficcional é criada a partir do ponto de vista dos vários narradores, ou seja, parte de suas subjetividades. Ao dar voz às mulheres como narradoras, Cardoso destaca suas subjetividades e suas verdades (ficcionais). Crônica da casa assassinada não é apenas uma narrativa sobre mulheres subversivas, mas também é contada por elas ${ }^{4}$. Os limites do poder masculino sobre a família e a verdade sobre as mulheres são questionáveis dentro da obra desde as primeiras gerações de Meneses, com as autoridades de Maria Sinhá e Dona Malvina, como vimos acima.

$\mathrm{O}$ tom de mistério favorece a criação de narradores que assumem um posicionamento de dúvida diante do mundo. Esta característica assemelha Lúcio aos romances modernos de seu tempo produtivo, como por exemplo To the lighthouse (1927), de Virginia Woolf. Os narradores em Lúcio Cardoso desconfiam, duvidam, procuram a verdade como se não a conhecessem, a fim de criarem uma realidade particular. Outra vez, Nina e Ana desorganizam a ordem patriarcal vigente. Elas questionam a realidade, a moral e as normas daquela sociedade. Além disso, são elas que detêm a verdade, são responsáveis e conhecedoras dos males que sobrevieram à chácara.

A personagem Ana, ao se olhar no espelho, percebe que foi criada para atender às expectativas do marido. Nesse momento, ela se sente insatisfeita com seu reflexo de mulher frágil, discreta e submissa às vontades de Demétrio ${ }^{5}$. A descrição que faz de si mesma recupera o texto de Freyre (1936). O retrato da mulher do patriarcado é pintado com aspectos de opacidade. O sociólogo chega a dizer que a fisionomia da mulher idealizada era aquela com aparência de doente, de apatia. Se havia sido "cultivada ao gosto dos Meneses" (CARDOSO, 1979, p. 99), depois, ela se sentirá “como se fosse uma outra mulher” (idem, p. 104), a ponto de confrontar o marido pela primeira vez.

A mudança de Ana é ainda mais significativa dentro do contexto em que se encontra. O insight para entender a imagem que via refletida acontece após a chegada de Nina no âmbito da família. A esposa de Valdo pode ser vista como um antagonismo à Ana. A personagem é filha de uma família suburbana e pobre do Rio de Janeiro. Sua mãe foi uma atriz sem prestígio que havia deixado ela e o pai para tentar carreira na Europa. Ao contrário de Ana, Nina é extravagante, vaidosa, veste-se de forma julgada como vulgar pelos moradores da pequena cidade mineira de Vila Velha - inclusive, há trechos em que as personagens

\footnotetext{
4 Entendemos que a afirmação pode levar a uma problematização sobre a autoria feminina e sobre a verossimilhança entre as identidades femininas reais e a identidade feminina criada por um escritor homem. Sem dúvida, isso pode ser feito em um trabalho futuro. A questão aqui é o destaque dado às subjetividades femininas dentro do projeto geral da obra - a destruição do patriarcado mineiro.

5 Nós nos referimos aqui a todo o capítulo oito do livro, "Primeira confissão de Ana".
} 
sugerem que ela fora prostituta antes de se casar com Valdo. Com a presença da cunhada, Ana encontra um parâmetro de comparação de feminilidade e percebe a possibilidade de assumir outros papéis e funções.

A relação entre as duas é conflituosa, porém, esconde uma admiração mútua. Por vezes, declaram-se inimigas, duas mulheres disputando o amor de um mesmo homem, Alberto. Todavia, em uma das passagens centrais do texto, as cunhadas se aproximam de maneira tal que "uma defronte da outra, [pareciam] tão idênticas como se fossem irmãs" (CARDOSO, 1979, p. 310). Ambas as personagens traem seus respectivos maridos com o jardineiro - Nina por amor, Ana por liberdade (idem, p. 313). Porém, a transgressão moral de Nina chega ao extremo no relacionamento amoroso com aquele que acredita ser o próprio filho, André. O incesto figura como um artifício poderoso contra a família. Podemos considerá-lo como um catalizador da ruína familiar. A escolha das temáticas do adultério e do incesto fazem parte da estrutura narrativa e colaboram com o projeto do escritor.

As mulheres possuem uma função decisiva em toda a narrativa. $\mathrm{O}$ foco narrativo, a escolha dos narradores, as temáticas tratadas, a polifonia, a subjetivação factual, o desenvolvimento do enredo, todas essas características evidenciam o destaque feminino e a tentativa de destruição do paradigma patriarcal.

\section{Considerações finais}

A partir da composição dos Meneses entendemos a família patriarcal e sua estratificação tradicional, ao mesmo tempo em que percebemos o pêndulo entre a forma real e a ideal. Em Crônica podemos reforçar a leitura que Mariza Corrêa faz dos textos de Gilberto Freyre. Ao analisar a família patriarcal devemos nos atentar para a distância entre um conceito generalizante, baseado mais em uma abstração, e os produtos concretos daquela realidade, as experiências. Quando falamos sobre família brasileira estamos diante de uma variedade de formas e contextos, ainda que nosso foco esteja no período colonial. Ao contrário do que transparece pela tradição teórica, a história da família não é linear, tampouco regular.

Entendemos o patriarcado como força dominante ainda hoje no pensamento a respeito dos relacionamentos domésticos. O discurso em favor da família patriarcal está no jornal, na 
política, na literatura, nas redes sociais, etc. Entretanto, não há como negar as rupturas que acontecem ao longo da história. Certamente que a economia, a urbanização, a industrialização e a ascensão da República contribuíram para a decadência do modelo. Mas, as fissuras acontecem também no interior do sistema através de um crime, um pecado, um adultério, um incesto. Essa é a importante contribuição da Crônica para os estudos culturais e feministas sobre o patriarcado e suas respectivas relações familiares e de gênero.

A Crônica da casa assassinada exprime uma alta complexidade narrativa e simbólica. Cada técnica e escolha artística serve ao objetivo anunciado por seu autor na entrevista ao Jornal do Brasil: "destruir a família mineira". Lúcio Cardoso ao declarar um ataque ao modelo familiar mineiro se refere à família patriarcal. Sendo assim, ao atacar um alicerce formado pela lógica masculina, ele se mune das personagens femininas, são elas que dão fim à família patriarcal na literatura. Se fora da ficção Cardoso afirma que ergue seu livro como um punhal contra Minas, na realidade ficcional são as mulheres que seguram o punhal contra os Meneses.

\section{Referências Bibliográficas}

BOSI, Alfredo. História concisa da literatura brasileira. São Paulo: Cultrix, 1994.

CARDOSO, Lúcio. [1959] Crônica da casa assassinada. São Paulo: Círculo do livro, 1979.

CARDOSO, Lúcio. Diários. (org.) Ésio Macedo Ribeiro. Rio de Janeiro: Civilização Brasileira, 2012.

CARDOSO, Lúcio. Lúcio Cardoso (patético): Ergo meu livro como um punhal contra Minas. Jornal do Brasil, Caderno B, Rio de Janeiro, 25 nov. 1960. Entrevista concedida a [Fausto Cunha]. Disponível em: http://memoria.bn.br/DocReader/030015_08/12458?pesq=punhal. Acesso em: 3 abr. 2019.

CORRÊA, Mariza. Repensando a família patriarcal brasileira. Cadernos de Pesquisa (Fundação Carlos Chagas), São Paulo, n 37, p. 5-12, 1981. Disponível em: http://publicacoes.fcc.org.br/ojs/index.php/cp/article/view/1590. Acesso em: 9 abr. 2019.

FREYRE, Gilberto. [1933]. Casa grande e senzala: formação da família brasileira sob o regime da economia patriarcal. 48. ed. São Paulo: Global, 2003. 
FREYRE, Gilberto. [1936]. Sobrados e mucambos: decadência do patriarcado e desenvolvimento do urbano. 16. ed. São Paulo: Global, 2006.

GLASER, André Luiz. Materialismo Cultural. 2008. Tese (Doutorado em Letras) Faculdade de Filosofia, Letras e Ciencias Humanas, Universidade de São Paulo, São Paulo, 2008. Disponível em: http://www.teses.usp.br/teses/disponiveis/8/8147/tde-03082009151710/pt-br.php. Acesso em: 4 abr. 2019.

LIMA, Marcos Hidemi de. Transgressão feminina em Crônica da casa assassinada: uma análise sobre Nina e Ana. Acta Scientiarum, Maringá, v. 38, n. 3, p. 281-290, 2016. Disponível.: http://periodicos.uem.br/ojs/index.php/ActaSciLangCult/article/view/29971/pdf. Acesso em: 10 abr. 2019.

NASCIMENTO, Evandro. Crônica de um crime anunciado. In: NASCIMENTO, Evandro. Ângulos: literaturas \& outras artes. Juiz de Fora: UFJF; Chapecó: Argos, 2002. p. 163-185.

SOUZA, Candice Vidal; BOTELHO, Tarcísio Rodrigues. Modelos nacionais e regionais de família no pensamento social brasileiro. Estudos feministas, Florianópolis, v. 9, n. 2, p. $414-$ 432, 2001. Disponível em: https://periodicos.ufsc.br/index.php/ref/article/view/S0104026X2001000200006/8851. Acesso em: 10 abr. 2019.

\begin{abstract}
The present essay analises the novel Crônica da casa assassinada (1959) by Lúcio Cardoso taking as guidance Gilberto Freyre's studies about the patriarchal family in Brazil. In it I suggest that the theme of decadence of such system has deep impact on its inner economy, which establishes an explicit dialogue with both - Freyre's and other sociology scholars' ideas which does not necessarily imply a mere mirroring process of social representation.
\end{abstract}

Keywords: Lúcio Cardoso; Crônica da casa Assassinada; Patriarchal family; Literature and society. 